\title{
USABILIDADE E AFETIVIDADE NO DESIGN DISTRIBUÍDO: UM ESTUDO SOBRE A QUALIDADE VISUAL E HÁPTICA PERCEBIDA DOS PRODUTOS UTILITÁRIOS FABRICADOS POR IMPRESSÃO 3D FFF POR LABORATÓRIOS INDEPENDENTES
}

\author{
Jose Ignacio Sanchez / UFPE \\ Germannya D`Garcia Araujo Silva / UFPE
}

\section{RESUMO}

O presente trabalho trata dos resultados parciais da pesquisa de mestrado que objetiva propor diretrizes para aumentar os ganhos na qualidade visual e háptica percebida de produtos utilitários fabricados por impressão 3D FFF em laboratórios independentes de fabricação digital no Brasil. A trajetória metodológica desenhada foi a replicação do modelo de design, distribuído entre 6 laboratórios, para fabricação dos produtos e avaliação da qualidade percebida dos fabricados, através de ferramentas de usabilidade com testes físicos e digitais. Como resultados parciais, apenas dois dos produtos foram avaliados de forma satisfatória do ponto de vista técnico. Acredita-se que a baixa compreensão da metodologia Design para Manufatura Aditiva (DFAM) dos makers pode ter colaborado para a baixa percepção da qualidade dos produtos pelos especialistas.

Palavras chaves: Design distribuído; Usabilidade; Afetividade, Experiência do usuário; Manufatura Aditiva.

\section{Introdução}

Os objetos resultantes da manufatura aditiva permitem a personalização de produtos proporcionando maior satisfação ao usuário, em particular os gerados por processos de cocriação, ou parceria, pois neste caso o utilizador tem uma participação mais ativa no método de design (Cunha e Providencia, 2020).

A cocriação de produtos é comum no Design Distribuído (DD), que é o resultado da interseção de duas tendências globais: o Movimento Maker ${ }^{1}$ e a digitalização da disciplina de design.

Esta digitalização junto com as ferramentas de fabricação digital permitiram a abertura de plataformas virtuais com base na cocriação de produtos e compartilhamento de dados. O projetista pode colocar produtos ou arquivos nestas plataformas e estes podem ser produzidos e modificados em qualquer lugar do mundo. No entanto, para que isso aconteça, é necessário que elas sejam construídas adequadamente e sendo necessário um entendimento completo dos diferentes aspectos da cocriação, e os papéis-chave dos sistemas de informação (Rayna, 2015).

A inovação do processo de criação livre e a complexidade dos procedimentos de entendimento entre prosumers ${ }^{2}$, em um contexto onde os laboratórios não possuem as mesmas especificações de máquinas, estão distribuídos em distintos espaços geográficos e os parâmetros técnicos do equipamento podem variar, trazem

\footnotetext{
${ }^{1}$ Movimento maker: Movimento baseado na ideia de que as pessoas devem ser capazes de fabricar, construir, reparar e alterar objetos dos mais variados tipos e funções com as próprias mãos, baseando-se num ambiente de colaboração e transmissão de informações entre grupos e pessoas.

${ }^{2}$ Prosumers: junção das palavras producer (produtor) e consumer (consumidor) e seu significa nada mais é que o consumidor que atua ao mesmo tempo como produtor e consumidor.
} 
como consequência um panorama suscetível para o acontecimento de falhas, comprometendo a qualidade percebida pelo usuário, e, consequentemente, gerando um aumento no consumo de materiais e de energia, o que por sua vez compromete os benefícios ambientais da tecnologia de fabricação por filamento fundido (FFF) (Greiesier, 20019).

Para além desses, outros problemas técnicos comuns desse novo modelo de produção já foram mapeados: interpretação equivocada do briefing por parte dos makers; insuficiência no tempo de pré-aquecimento da máquina; falhas mecânicas na impressora e a geometria inadequada das peças. Para esta última, acredita-se que a competência do desenvolvedor do produto também deve ser investigada (Sanchez e D'Silva,2020).

No que se refere a satisfação dos usuários, os autores desta pesquisa acreditam ainda que é preciso aumentar o número de investigações para estabelecer diretrizes básicas em relação aos fluxos de trabalho e metodologias aplicadas à fabricação de artefatos pelo modelo do design distribuído. Esta motivação, suscitou replicar parcialmente o sistema de design distribuído com a impressão 3D para produtos utilitários junto a laboratórios independentes, para entender quais são os aspectos técnicos e subjetivos relacionados com a qualidade do produto final.

O presente artigo apresenta os primeiros resultados da pesquisa de mestrado em andamento, que objetiva propor diretrizes para avaliação da qualidade visual e háptica percebida de produtos utilitários fabricados por impressão 3D FDM (fused deposition modeling) em laboratórios independentes de fabricação digital.

\section{Fundamentação Teórica}

\subsection{Design distribuído com ênfase na distribuição de produtos através de dados}

O Design Distribuído levou ao surgimento de um novo mercado, no qual indivíduos criativos possuem acesso às ferramentas digitais que Ihes permitem projetar, produzir e fabricar produtos ou se conectar facilmente a uma rede global de colaboradores para compartilhar entre si aspectos desse processo.

Essa colaboração através de plataformas virtuais pode ser expressa no movimento open source que incentiva centenas de milhares de pessoas que atuam em grandes redes de criação de valor digital, produzindo bens tais como: conhecimento, ciência, software, serviços, conteúdos virtuais e produtos físicos. Acima de tudo, estes bens estão disponíveis para qualquer pessoa que se sinta livre para adquirir esse conhecimento e transformá-lo em produto (Diez, 2018).

Alguns autores da área apontam que para a criação de um artefato em fabricação digital com qualidade satisfatória é necessário o domínio de três dimensões do processo: o Software, o Hardware e os Materiais. Sendo o domínio do Software, a fase da construção da ideia e formatação dos arquivos; o domínio do Hardware, a fase de decisão dos parâmetros de injeção da impressora 3D e por fim, o domínio dos Materiais, a fase de seleção dos polímeros (caso da FFF). A escolha incorreta de uma máquina ou de um material para a produção de um produto é uma das principais causas de falhas e custos desnecessários nos laboratórios de fabricação digital (ROMEIRO, 2010; COSTA, 2018). 
Os procedimentos utilizados em laboratórios fechados nas indústrias, a fim de diminuir as falhas no processo de impressão 3D, estão contemplados na metodologia de design para manufatura aditiva (DFAM). Esta consiste em criar os arquivos a serem impressos em 3D de modo a obter sua máxima eficiência. O objetivo do DFAM é potencializar o desempenho do produto através da síntese de formas, tamanhos, estruturas hierárquicas e composições de materiais, de acordo com a capacidade de cada tecnologia. Assim, é fundamental que o desenvolvedor do produto verifique sistematicamente as etapas do processo de fabricação aditiva para prever possíveis falhas (GIBSON et al, 2010; SOSSOU et al, 2018).

Os autores desta pesquisa acreditam que o uso do DFAM pode colaborar com o desafio do design distribuído atendendo às demandas de produção local mais rapidamente, unificando ou criando uma linguagem comum entre os makers, a fim de disponibilizar os arquivos para os distintos processos de produção dentro dos laboratórios independentes, garantindo uma boa experiência de uso aos consumidores.

\subsection{Usabilidade e Qualidade Percebida dos Produtos Fabricados por Adição}

As características formais de um objeto oferecem ao sujeito recursos funcionais e de usabilidade, mesmo sem realizar um exame mais profundo do produto em si. Nessa relação entre sujeito e objeto, primeiro, o sujeito elabora uma estratégia perceptiva inconsciente para verificar se o objeto, por sua concepção e características formais, pode trazer-Ihe alguma emoção/benefícios (certo prazer no uso); depois, ele concentra sua atenção nas características funcionais e de usabilidade (NORMAN 2002).

Enquanto conceito, a usabilidade é a medida para avaliar três princípios básicos que os usuários esperam encontrar em um artefato: eficácia, eficiência e satisfação. A eficácia refere-se à extensão na qual uma meta é alcançada ou uma tarefa é realizada; a eficiência aponta à quantidade de esforço requerido para se atingir uma meta, ou seja, quanto menor o esforço, maior é a eficiência; enquanto que a satisfação trata do nível de conforto que os usuários sentem quando utilizam um produto ou sistema e também o nível de aceitação pelos usuários para atingirem suas metas (JORDAN, 2002;PETERS Et al, 2002) .

Embora se reconheça que a usabilidade é um componente chave para garantir uma agradável experiência de uso, os elementos estéticos de um produto e as associações experienciais que os usuários atribuem a tais propriedades como: forma, cor e propriedades táteis, são outros fatores que influenciam o prazer de uso de um artefato (JORDAN, 2002; NORMAN, 2006).

Especificamente no processo de pedido do produto através de plataformas online, e principalmente na co-criação, quando se trata de um produto "sob demanda" em que a referência são apenas de renders, os elementos estéticos influenciam na usabilidade aparente do produto, que é a percepção dos usuários quanto à facilidade de uso de determinado artefato na fase que antecede a sua utilização. Já as avaliações dos usuários quanto à percepção de conforto, bem-estar, alegria e satisfação após o uso efetivo do produto pode ser chamada de usabilidade percebida e ambas, influenciadas pelos aspectos estéticos-simbólicos, são avaliadas de forma subjetiva (PASCHOARELLI Et al, 2015).

Isto posto, a qualidade desta relação entre as pessoas e os produtos depende mais do que simplesmente da usabilidade do produto. São as emoções que desempenham um papel crítico no cotidiano, 
ajudando a aceder a situações de intensidades "boas ou más", "seguras ou perigosas", pois são as emoções que ajudam a tomar decisões. As emoções são parte dos mecanismos bio-reguladores com os quais nascemos equipados, visando à sobrevivência (DAMÁSIO, 2000).

Do ponto de vista ergonômico, a compreensão das emoções negativas, normalmente serve como base para o estabelecimento dos requisitos para a melhoria da usabilidade dos produtos e sistemas. Uma vez satisfeitos os requisitos de funcionalidade e usabilidade, o que se objetiva alcançar com um projeto mais afetivo são as prioridades psicológicas e sociológicas do usuário, como suas necessidades de pertencer, alcançar, ser competente e independente, tornando a interação uma experiência prazerosa (HANCOCK, 2005).

Desta forma, o valor atribuído a um objeto, seja ele de utensílios ou tecnológicos, está diretamente relacionado à experiência afetiva do usuário. Ou seja, a emoção implica nas escolhas que fazemos e não só na qualidade de uso que os produtos oferecem às pessoas. (MARIÑO, 2017)

O aumento no valor de um produto de consumo é alcançado quando os usuários finais recebem um grau mais alto de influência direta e deliberada sobre a forma do produto; desde a identificação do um produto e a suas características necessárias para satisfazer necessidades do usuário, até o envolvimento no processo de design pelo qual é chegada a uma solução acordada entre o designer e o usuário final (SINCLAIR,2014).

A impressão 3D tem a capacidade de promover emoções positivas, através da customização de produtos, uma vez que possibilita a personalização de um artefato e aumenta seu valor agregado. A possibilidade dos usuários criarem produtos junto com designers, engenheiros ou makers é chamado de "co-design".

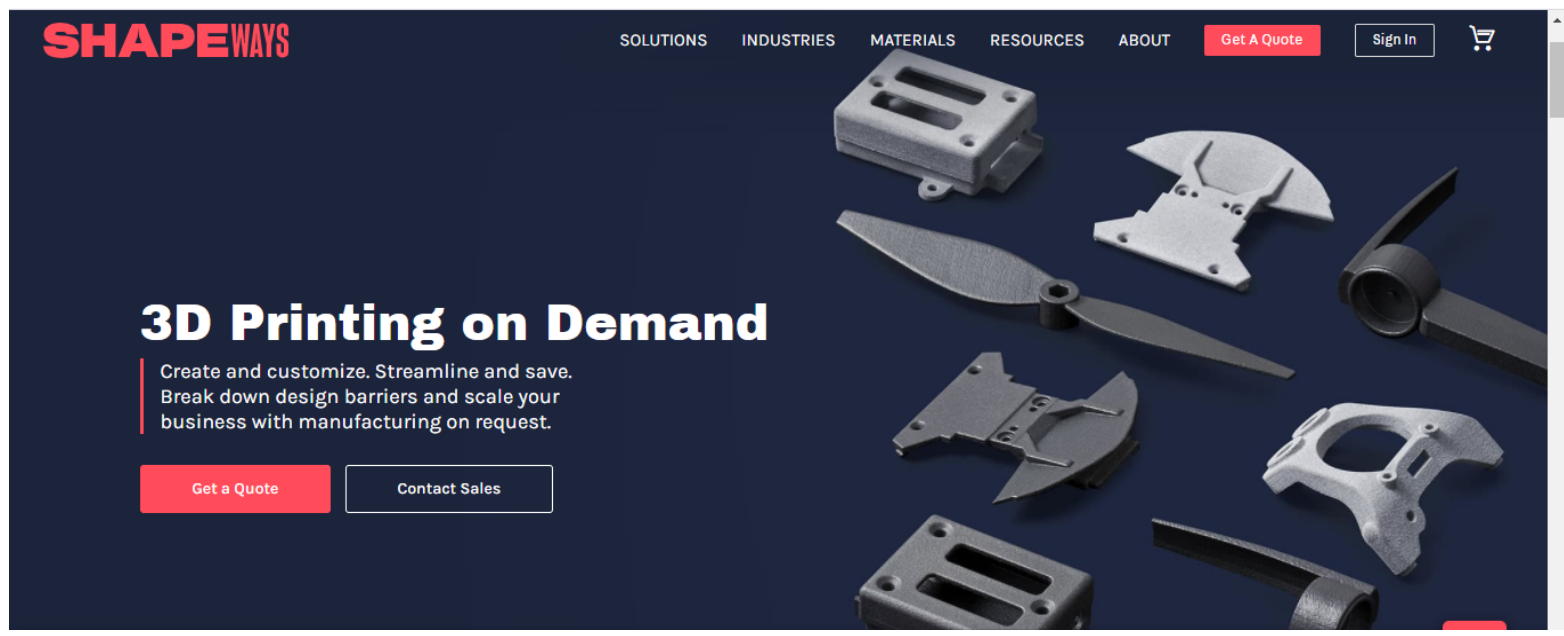

Figura 1: Site shapeways dedicado a produzir produtos de forma Sobre demanda. Fonte: https://www.shapeways.com/

A impressão 3D está na base do conceito de co-design, onde o usuário fornece elementos que vão ser usados na construção do produto com variados graus de personalização, como é o caso dos produtos das empresas Shapeways.com, Figura 1 (CUNHA e PROVIDENCIA, 2020). No entanto, poucos usuários estão acostumados a produtos impressos em 3D, por isso, eles acabam estabelecendo relações com os objetos anteriores da mesma área. A interação com esses produtos fabricados, através de um novo processo com distintos materiais, traz uma experiência nova para os consumidores. 
A importância atribuída ao objeto pelo usuário e as circunstâncias de compra criam uma história dentro do repertório de conhecimento do usuário. Esta sobreposição de experiências prossegue através da vida do objeto, uma vez que as memórias são armazenadas através do tato e o usuário as estabelece a partir de eventos, lugares e pessoas ligadas ao objeto [23].

Na prática, deveria ser função do designer/maker equilibrar as propriedades objetivas e subjetivas, entre a tecnologia funcional e a expressividade emocional; entre a informação e a inspiração; entre a compreensão e o afeto, para atender às expectativas desses usuários.

\section{Trajetória Metodológica}

Um método composto de 3 fases foi proposto para avaliação dos produtos produzidos pelos laboratórios independentes verificando a relação entre o consumidor final e o maker: Fase 1 - Seleção de arquivos e dos Laboratórios Independentes para replicar parcialmente o modelo de "Design Distribuído"; Fase 2 - Serviço de Design dos Laboratórios envolvidos na pesquisa. Nesta fase não foi avaliado o serviço do maker, e sim, o produto resultante deste serviço; Fase 3 - Avaliação da qualidade percebida dos produtos através de testes visuais e físicos do produto junto aos especialistas em manufatura aditiva (Figura 2).

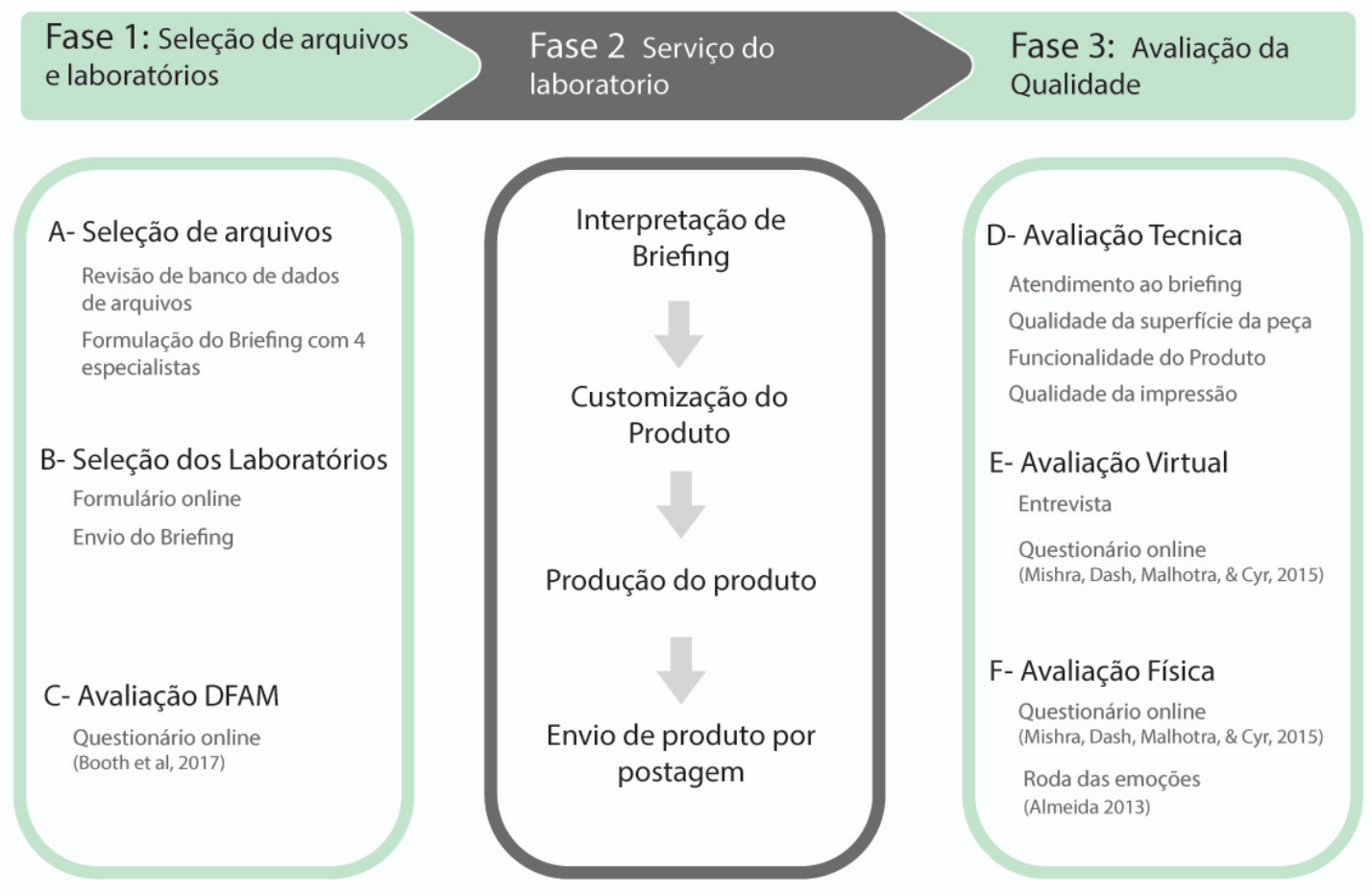

Figura 2: Método para desenvolvimento da pesquisa Fonte: Os autores

Este artigo apresenta os procedimentos e resultados das fases 1 e 2, e os da fase 3 para todas as etapas. Contudo, apenas os resultados da etapa " $D$ " referentes a qualidade técnica e de uso serão apresentados, uma vez que os resultados das subsequentes referentes às questões da afetividade ainda estão sendo processados. 


\section{Resultados parciais}

\section{Fase 1}

\section{A / Seleção do arquivo para impressão}

Para a escolha do arquivo foram revisados e pré-selecionados seis produtos utilitários da plataforma virtual thingirverse.com (banco de dados de arquivos), selecionada por conter um número significativo de arquivos disponíveis. Para apoiar na seleção do arquivo, cinco especialistas e coordenadores de laboratórios de impressão 3D, da cidade do Recife, Pernambuco - Brasil foram contactados.

A Figura 3, apresenta a classificação dos produtos pelos especialistas, sendo a menor quantidade de pontos o melhor produto avaliado. Desta análise os produtos "amarrador de cadarço" e "colher de medição" tiveram uma classificação muito próxima, todavia, o número de customizações que os produtos possuiam na plataforma "thingirverse.com" foi o critério de seleção utilizado para apoiar a decisão.

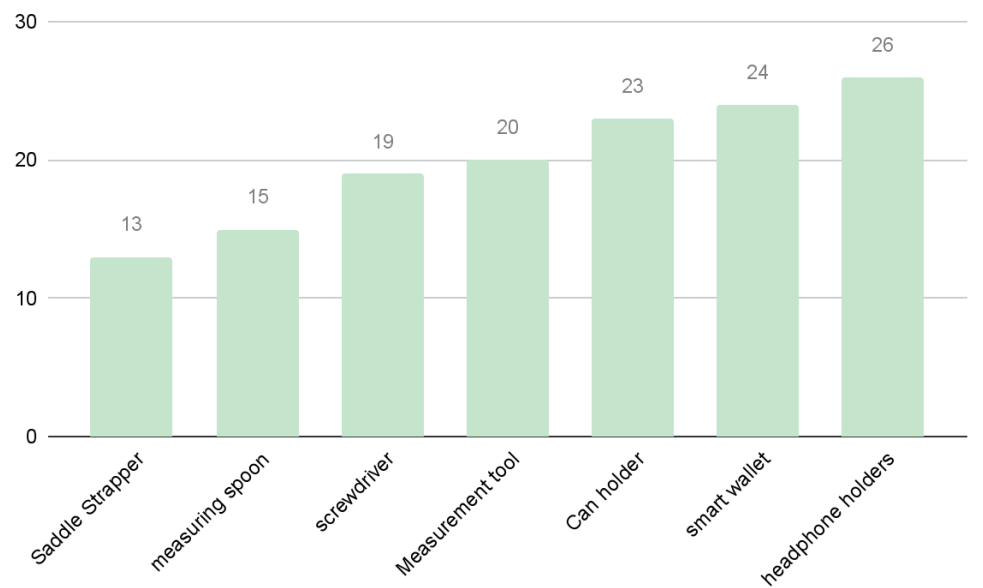

Figura 3. Gráfico de avaliação de arquivos selecionados.

Fonte: Os autores

O amarrador de cadarço "Klots" projetado para substituir a forma em que comumente amarramos os cadarços foi o produto selecionado como o objeto para o experimento (Figura 04). 


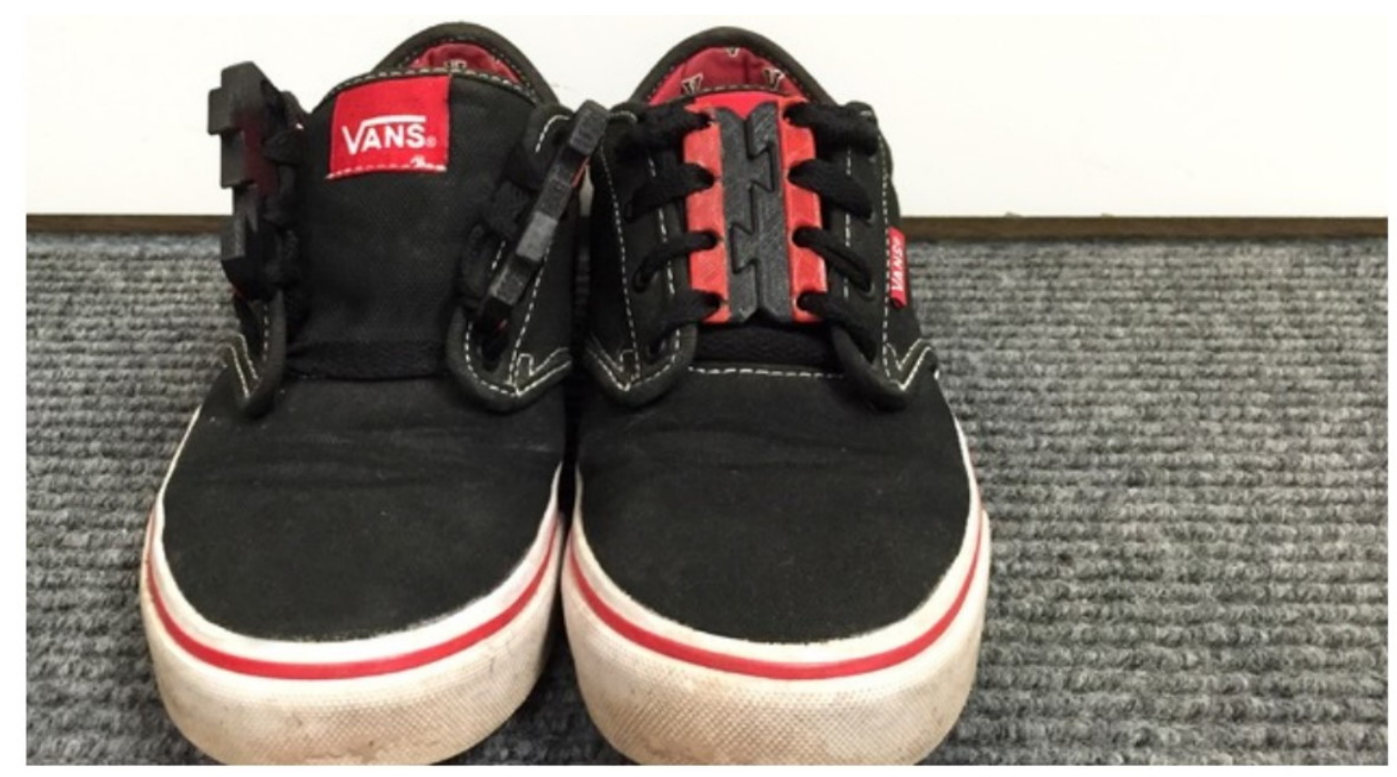

Figura 4: Produto "Klots" usado em tênis .

Fonte: Thingirverse.com , 2018

Para composição do briefing foi solicitado aos makers que aplicassem dois tipos de customização: 1) Agregar mais um furo ao produto Klots e 2) Modificar a forma do encaixe original para uma forma mais circular (Figura 5).

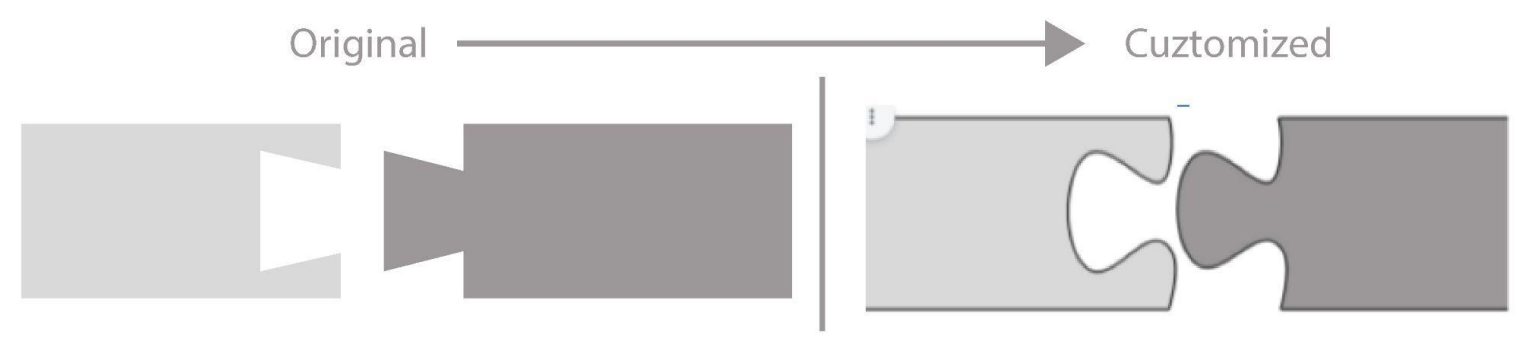

Figura 5. Encaixe referente ao briefing enviado para os laboratórios independentes. Fonte: os autores.

B| Seleção dos laboratórios independentes:

Para a seleção dos laboratórios independentes foi adotada a plataforma virtual brasileira makerfind.org, que objetiva conectar laboratórios independentes aos clientes no Brasil. Os critérios de seleção foram: os laboratórios cadastrados entre 2020 e 2021; possuir filamentos ABS na cor branco e impressoras 3D FFF de modelo aberto. Foram selecionados seis laboratórios independentes dos estados: Rio de Janeiro, São Paulo, Pernambuco e Bahia.

C| Avaliação DFAM

Para avaliar a competência do executor sobre impressão 3D foi elaborado um questionário desenvolvido com base no trabalho de Booth et al, 2017 e Alafaghani et al, 2017 com perguntas relacionadas ao método de design para manufatura aditiva (DFAM). 


\section{Fase 2}

\section{Serviço do Laboratório}

Os laboratórios escolhidos receberam os arquivos STL, junto com o briefing de customização. Eles tiveram que interpretar, customizar, imprimir, fotografar e enviar o produto seguindo as instruções do briefing.

Os seis artefatos produzidos através da manufatura aditiva receberam códigos arbitrários (Tabela 1) para manter o anonimato dos laboratórios, além de tornar possível comparar a qualidade técnica dos produtos produzidos, bem como avaliar os resultados através do teste de conhecimento em DFAM.

Tabela 1. Produtos fabricados por laboratórios independentes com seus respectivos códigos. Fonte: Os autores

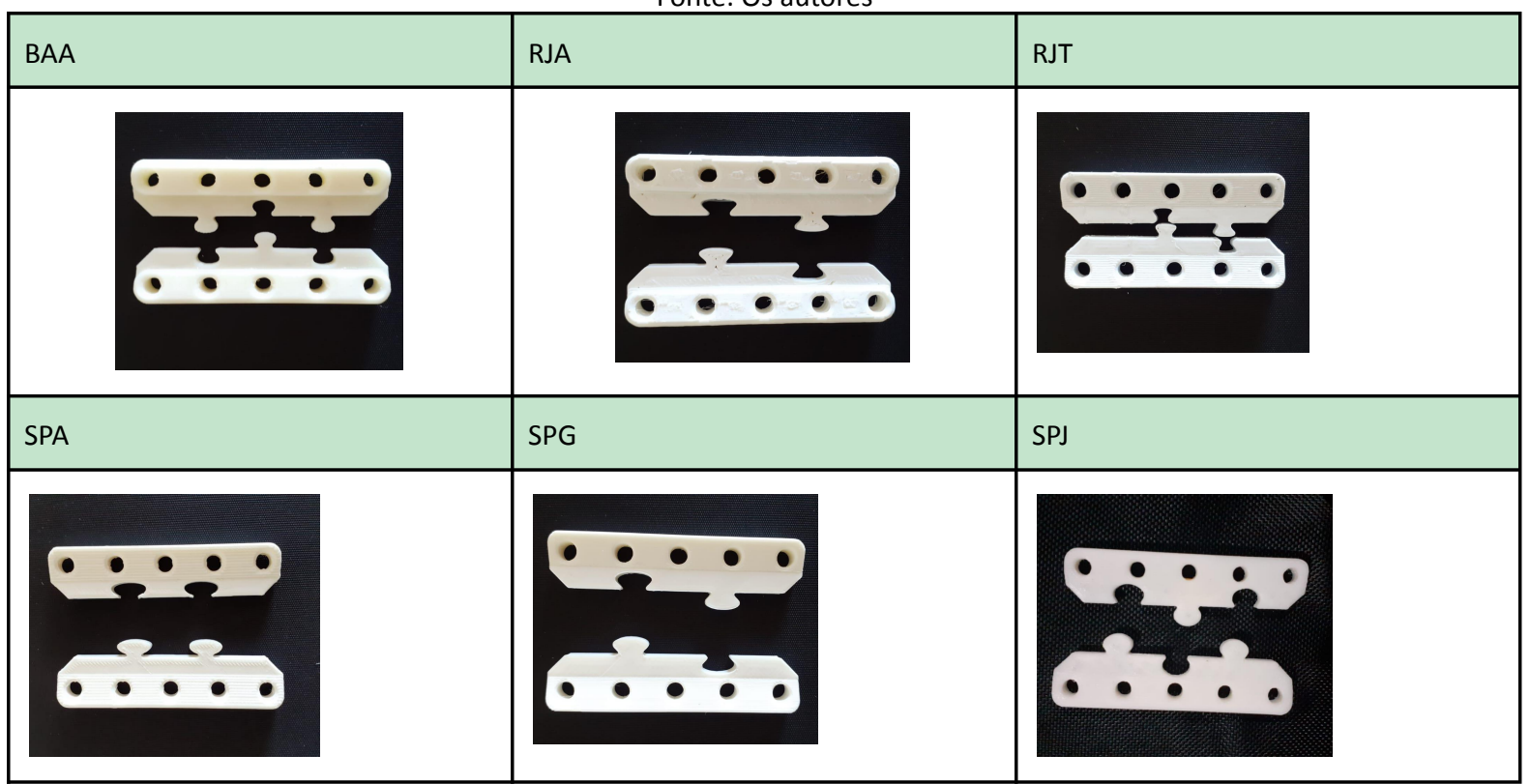

\section{Fase 3}

Avaliação da qualidade do produto

D | Avaliação técnica

A análise técnica dos produtos realizada pelo autor da pesquisa pautou-se na avaliação dos itens: Atendimento ao briefing; Qualidade superfície da peça; Funcionalidade do produto; Qualidade da impressão. Cada um deles foi avaliado através de três intensidades: Alta, Média e Baixa ou mesmo, se atendia aos critérios propostos (Tabela 2). A formação de base do maker, o conhecimento de design sobre manufatura aditiva e o tempo de experiência de cada laboratório (em meses) também foram avaliados. 
Tabela 2. Avaliação técnica da qualidade dos produtos impressos através do DD. Fonte: Os autores.

\begin{tabular}{|c|c|c|c|c|c|c|}
\hline \multirow[b]{2}{*}{ Produtos x Parâmetros } & & \multirow[b]{2}{*}{ RJT } \\
\hline & BAA & SPJ & SPG & SPA & RJA & \\
\hline \multicolumn{7}{|c|}{ Em relação ao produto } \\
\hline Atendimento ao briefing & Alta & Alta & Médio & Médio & Baixo & Baixo \\
\hline Qualidade da superfície da peça & Alta & Alta & Alta & Alta & Baixa & Médio \\
\hline Funcionalidade do Produto & Alta & Médio & Alta & Alta & Alta & Baixa \\
\hline Qualidade da impressão & Alta & Alta & Alta & Alta & $\operatorname{sim}$ & Sim \\
\hline \multicolumn{7}{|c|}{ Em relação ao Laboratório Independente } \\
\hline Formação Básica & $\begin{array}{l}\text { Eng. } \\
\text { Autom } \\
\text { otivo }\end{array}$ & $\begin{array}{l}\text { Eng. } \\
\text { Mecânica }\end{array}$ & $\begin{array}{l}\text { Eng. } \\
\text { Mecânica }\end{array}$ & $\begin{array}{l}\text { Desenho } \\
\text { Industrial }\end{array}$ & $\begin{array}{l}\text { Ciências } \\
\text { Computaç } \\
\text { ão }\end{array}$ & $\begin{array}{l}\text { Eng. } \\
\text { Mecânic } \\
\text { a }\end{array}$ \\
\hline $\begin{array}{l}\text { Tempo de atuação como maker } \\
\text { (meses) }\end{array}$ & 24 & 24 & 6 & 60 & 12 & 36 \\
\hline Conhecimento em DFAM & $\begin{array}{l}\text { Baixo } \\
7 / 14\end{array}$ & $\begin{array}{l}\text { Medio } \\
8 / 14\end{array}$ & $\begin{array}{l}\text { Baixo } \\
6 / 14\end{array}$ & $\begin{array}{c}\text { Medio } \\
9 / 14\end{array}$ & $\begin{array}{l}\text { Medio } \\
10 / 14\end{array}$ & $\begin{array}{l}\text { Medio } \\
14 / 10\end{array}$ \\
\hline
\end{tabular}

E| Avaliação Virtual (Processando dados):

Neste estudo, foi realizada uma etapa de Avaliação Virtual qualitativa através de entrevistas sistematizadas com os especialistas voluntários da pesquisa. Os produtos impressos foram primeiramente apresentados de forma virtual aos especialistas. Estes, mediante a percepção da usabilidade aparente, preenchiam um formulário adaptado do trabalho de Mishra (2015) e Meng (2019) no formato de Escala de Likert, divididas em duas sessões: "Experiência de uso" e "Usabilidade do produto" .

F| Avaliação Física (Processando dados):

Na etapa da Avaliação Física, também qualitativa, foi repetido o formulário aplicado na fase "E", sendo, neste caso, avaliado a partir de produtos de forma física. Na sequência, foi aplicada a ferramenta de "Rodas das Emoções" utilizada por Desmet (2004), Dias (2009) e Almeida (2013). Esta ferramenta, que avalia a intensidade de quatorze emoções, divididas em sete positivas e sete negativas, com três níveis de intensidade, foi selecionada como o modelo de avaliação para obter uma escala de afeto. Os especialistas foram convidados a atribuírem valor para uma ou mais emoções evocadas no contato com os produtos fabricados através do DD.

\section{Considerações parciais da pesquisa}

A pesquisa de mestrado ainda está em andamento, mas já é possível estabelecer algumas relações entre a satisfação do usuário final e os produtos produzidos no modelo Design Distribuído no Brasil. Como resultados parciais, pode-se perceber que apenas um dos seis produtos apresentou erros técnicos comuns envolvendo o manuseio da máquina ou do material: insuficiência no tempo de pré-aquecimento da máquina; falhas mecânicas e de calibração na impressora 3D. Este fato é indicativo de um panorama positivo dentro dos 
serviços de impressão 3D no Brasil, com arquivos que já foram testados anteriormente, pois cinco dos seis produtos avaliados, não apresentaram falhas visíveis na topografia da peça.

Contudo, os erros mais frequentes neste experimento e que comprometeram a satisfação do usuário envolveram o uso de softwares de modelagem 3D; a interpretação do briefing; o escalamento do material e a dificuldade para customizar um arquivo previamente projetado.

Os baixos resultados no teste de design para manufatura aditiva (DFAM), junto com a variação dos resultados da percepção da qualidade dos produtos, demonstram que o sucesso das plataformas que trabalham com o design distribuído não está associado apenas com o tempo de experiência e conhecimento dentro da área de fabricação digital. A comunicação por parte do maker com o cliente e a auto avaliação da qualidade dos resultados parciais dos produtos são imprescindíveis no processo de cocriação e influencia diretamente na qualidade percebida do produto.

Adicionalmente, visto o notório baixo conhecimento no tema, a falta de uma metodologia de design para manufatura aditiva pode ter influenciado significativamente os baixos resultados de qualidade percebida nos produtos.

\section{Referência}

ALMEIDA, G. Avaliação dos aspectos subjetivos relacionados aos materiais :proposição de método e escalas de mensuração aplicadas ao setor moveleiro. 2013. p. 191. Disponível em: <http://www.ppgd.uemg.br/wp-content/uploads/2014/05/Dissertação-Gilberto-Almeida-Jr.pdf>. SINCLAIR, M.;

CAMPBELL, I. A Classification of Consumer Involvement in New Product Development. Proceedings of DRS

2014: Design's Big Debates., 2014. n. May, p. 1582-1598. Disponível em: <http://www.drs2014.org/media/745827/drs14_proceedings.pdf>.

DIAS, M. R. Á. C. Percepção dos materiais pelos usuários: modelo de avaliação Permatus. 2009. Disponível em: <http://repositorio.ufsc.br/handle/123456789/92232>.

DIEZ, T. Fab City the mass distribution of almost everything. 1rst. ed. Barceloma: [s.n.], 2018.

ROMEIRO FILHO, E. et al. Projeto de Produto. Elsevier E ed. Rio de Janeiro: Elsevier Editora Ltda, 2010.

GIBSON, I.; ROSEN, D. W.; STUCKER, B. Additive Manufacturing Technologies. Atlanta: Springer is, 2010.

PASCHOARELLI, L. C. P.; CAMPOS, L. F. De A.; SANTOS, A. D. P. DOS. A influência da estética na usabilidade aparente: aspectos para a criatividade e inovação no design de sistemas e produtos. ARTE-CIÊNCIA PROCESSOS CRIATIVOS. 1. ed. São Paulo: Cultura Acadêmica, 2015, p. 1-5.

JORDAN, P. W. An Introduction to Usability. London: Taylor and Francis, 1998.

MARIÑO, S. et al. a Interação Projetual Entre a Ergonomia E a Emoção: Uma Proposta De Definição De Requisitos Projetuais Para O Design De Produtos a Partir Da Opinião Dos Usuários. $16^{\circ}$ Ergodesign - Congresso Internacional de Ergonomia e Usabilidade de Interfaces Humano Tecnológica: Produto, Informações Ambientes Construídos e Transporte, 2017. p. 1138-1149. 
MISHRA, A.; DASH, S.; MALHOTRA, N. Measuring consumer design perceptions for digital devices: A multi-dimensional scale. Brand Manag, 2015. v. 22, p. 603-630.

SANCHEZ, JOSE IGNACIO, G. Uma Revisão Sistemática da Literatura sobre os Processos de Design direcionados a Manufatura Aditiva em Fab Labs para melhoria da qualidade do produto e redução de resíduos. 2020.

BOОтH, J. W. et al. The design for additive manufacturing worksheet. Journal of Mechanical Design, Transactions of the ASME, 2017. v. 139, n. 10, p. 1-9.

PETERS, E. R. et al. Perceptual organization deficits in psychotic patients. Psychiatry Research, 2002. v. 110, n. 2, p. 125-135. GREIESIER, F. 16 Common 3D Printing Problems and Solutions. 2019. Disponível em: <https://all3dp.com/common-3d-printing-problems-and-theirsolutions/.>. Acesso em: $1^{\circ}$ dez. 2019.

ALAFAGHANI, A.; QATTAWI, A.; ABLAT, M. A. Design Consideration for Additive Manufacturing: Fused Deposition Modelling. Open Journal of Applied Sciences, 2017. v. 07, n. 06, p. 291-318.

SOSSOU, G. et al. An additive manufacturing oriented design approach to mechanical assemblies. Journal of Computational Design and Engineering, 2018. v. 5, n. 1, p. 3-18. Disponível em: <https://doi.org/10.1016/j.jcde.2017.11.005>.

RAYNA, T.; STRIUKOVA, L.; DARLINGTON, J. Co-creation and user innovation: The role of online 3D printing platforms. Journal of Engineering and Technology Management - JET-M, 2015. v. 37, p. 90-102. Disponível em: <http://dx.doi.org/10.1016/j.jengtecman.2015.07.002>.

CUNHA, J.; PROVIDÊNCIA, B. PERCURSOS DO DESIGN EMOCIONAL. 2C2T-Lab. ed. Guimarães: 2C2T - Lab, 2020.

COSTA, C.; PELEGRINI, A. Design Distribuído: novas práticas e competências para o design. Joinville: $\mathbf{1 3}^{\circ}$ Congresso Brasileiro de Pesquisa e Desenvolvimento em Design, Univille, Joinville (SC), 2018. YIN, R. K. And Methods ( Applied Social Research Methods ). 2003.

NORMAN, D. Emotional Desing: what we love (or hate) everyday things. New York: Taylor and Francis, 2006.

DAMASIO, A. O mistério da consciência Do corpo e das emoções ao conhecimento de si. 2da. ed. São Paulo: SCHWARCZ LTDA., 2000.

HANCOCK, P. A.; PEPE, A. A.; MURPHY, L. L. Hedonomics: The power of positive and pleasurable ergonomics. Ergonomics in Design, 2005. v. 13, n. 1, p. 8-14. 